\title{
СТРУКТУРНАЯ КЛАСТЕРИЗАЦИЯ ИННОВАЦИОННЫХ РЕШЕНИЙ В СФЕРЕ ОБНОВЛЕНИЯ НЕФТЕПРОМЫСЛОВОГО ОБОРУДОВАНИЯ В КОНТЕКСТЕ ОЦЕНКИ МАРКЕТИНГОВОЙ НАДЁЖНОСТИ ДЛЯ ЦЕЛЕЙ РАЗВИТИЯ ЛИЗИНГОВОЙ КОМПАНИИ
}

\author{
(c) 2021 Рудская Ирина Андреевна \\ доктор экономических наук, Высшая инженерно-экономическая школа \\ Санкт-Петербургский политехнический университет Петра Великого, Россия, Санкт-Петербург \\ E-mail: rudskaya_ia@spbstu.ru \\ (c) 2021 Куракин Владимир Иванович \\ соискатель, Высшая инженерно-экономическая школа \\ Санкт-Петербургский политехнический университет Петра Великого, Россия, Санкт-Петербург \\ E-mail: v.i.kurakin@yandex.ru
}

На сегодняшний день процесс технологического развития становится все более стремительным. Фактически экспоненциальная динамика цифровизации оказывает влияние на ускорение разработки и интеграции технологических инноваций практически во всех отраслях промышленности. Следствием данной динамики является необходимость инвестиций в технологическое развитие на наиболее ранних этапах появления инновационных решений. Особую значимость данный процесс имеет для лизинговых компаний. В рамках статьи [1] авторами был предложен инструмент оценки маркетинговой надежности инновационных решений, позволяющий сравнить потенциальную технологическую устойчивость инновационных альтернатив. В рамках данной статьи авторы приводят результаты апробации данного алгоритма применительно к сфере нефтепромыслового оборудования и формулируют системные выводы.

Ключевые слова: маркетинговая надежность, нефтепромысловое оборудование, лизинг, инновационные решения, информационная среда.

В рамках статьи [1] представлен разработанный авторами аналитический инструментарий оценки маркетинговой надежности. Данный инструментарий является крайне актуальным для целей анализа в рамках лизинга в сфере обновления нефтепромыслового оборудования. Апробация разработанного алгоритма структурной кластеризации инновационных решений применительно к исследованиям и разработкам в области нефтепромыслового оборудования позволит сформулировать системные выводы относительно ключевых направлений развития лизинговой компании. Первичным этапом разработанного алгоритма является идентификация содержательных кластеров, описывающих основные направления исследований и разработок в сфере нефтепромыслового оборудования. Данный анализ производится на основе 1000 заголовков тематических статей, автоматически извлекаемых из ресурса ScienceDirect. В качестве поискового запроса был выбран универсальный N-грамм - «Oilfield equipment».
Алгоритм k-средних позволил установить, что наибольшая силуэтная оценка составляет 0,12 для 4 содержательно-тематических кластеров. Рассмотрим последовательно каждый из них.

Кластер 1 объединяет в себе токены, описывающие исследования в отрасли коррозийной устойчивости, в частности повышение данных свойств за счет управления свойствами вещества на нано уровне. В качестве токеновцентроидов данного кластера можно выделить «corrosion», «nanoparticles», «nanomaterials» и «nanocomposite». В качестве токенов-стеллитов можно выделить «exploration», «stainless» и многие другие. Таким образом, токен-концентратор может быть сформулирован как «Nanotechnology to reduce corrosion». Актуальность данного кластера объясняется потенциально значимыми затратим предприятия, связанными с обеспечением процесса обновления оборудования, подверженного коррозийному износу. Содержательная модель данного кластера представлена на рисунке 1. 


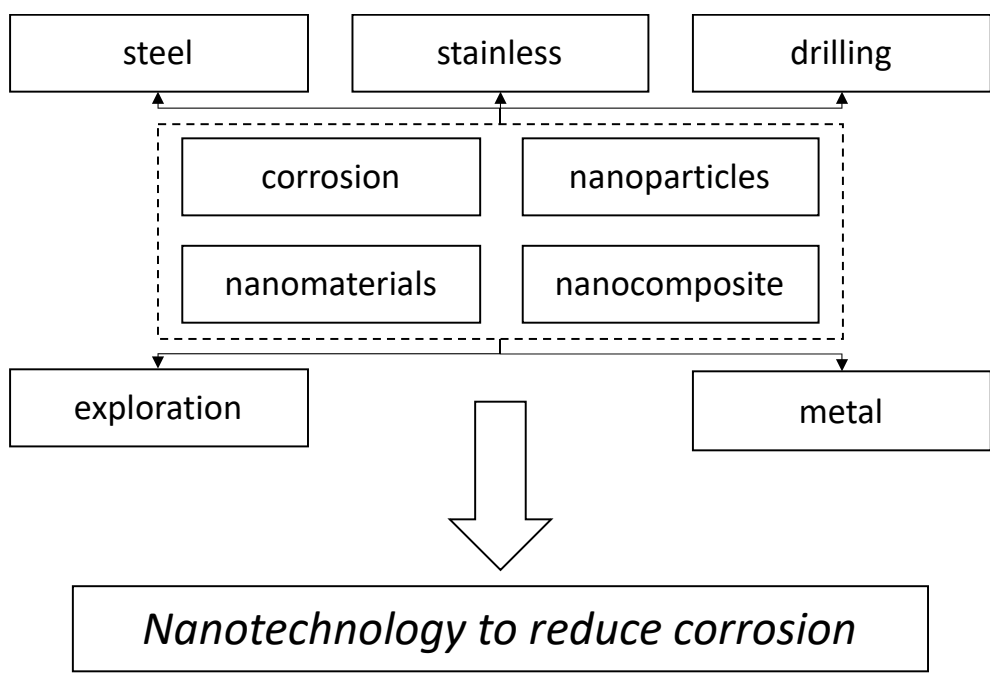

Рисунок 1. Содержательное модель кластера 1.

Кластер 2 значительно менее технологи- «wastewater», «geochemistry» и иные. Таким обчески конкретный в сравнении с кластером 1. разом, в качестве токена-концентратора можДанный кластер посвящен исследованию эко- но выделить - «Environmental aspect of mining логических аспектов процесса добычи полезных ископаемых, в частности нефти и природного газа. Актуальность данного кластера во много определяется развитием концепции устойчивого развития, одним из определяющих элементов которой является экологическая составляющая. Соответственно, в ближайшей перспективе в рамках развития лизинговой деятельности в отношении нефтепромыслового оборудования все большее значение будет иметь уровень экологической устойчивости предлагаемых технологических решений. Токенами-центроидами в данном случае выступают «hydrophilic», technologies». Содержательная модель данного кластера представлена на рисунке 2.

Кластер 3 является наиболее широким с точки зрения объединенных в его рамках групп технологических решений. Данный кластер объединяет в себе совокупность исследований, посвященных добыче природного газа. Актуальность данного кластера во многом определяется общемировой направленностью на увеличение доли природного газа в рамках выработки энергии. Данный тренд во многом обусловлен большей экологичностью природного газа, как энергоносителя, а также относи«ecological», «geothermal», и «hydrocarbon», а тельно более низкой стоимостью процесса дотокенами-сателлитами в свою очередь «thermal», бычи. Токенами-центроидами в данном случае

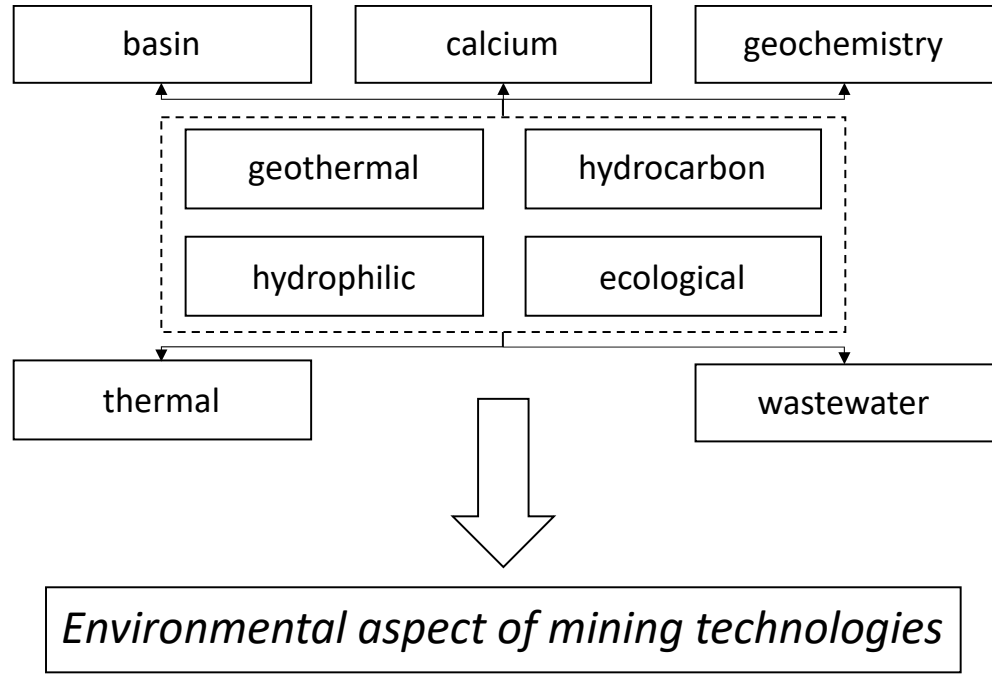

Рисунок 2. Содержательное модель кластера 2. 
выступают «gas», «со2», «carbon», и «methane», а токенами-сателлитами в свою очередь «diffusion», «natural», «carbonate» и иные. Таким образом, в качестве токена-концентратора можно выделить - «Gas production technologies». Содержательная модель данного кластера представлена на рисунке 3.

Кластер 4 является завершающим, и объединяет в себе исследования, посвящённые морской добычи нефти и газа. Актуальность исследований в данной области обусловлена относительным исчерпанием сухопутных запасов нефти и газа, что мотивирует нефтедобывающие компа- нии разведывать запасы углеводородов, расположенные в море. Таким образом, в ближайшие годы все более значимыми в рамках лизинга будут технологические решения, направленные на добычу нефти и газа в море (в частности, на Арктическом шельфе). Токенами-центроидами в данном случае выступают «water», «со2», «marine», и «offshore», а токенами-сателлитами в свою очередь «reservoir», «fluid», «thermal» и иные. Таким образом, в качестве токенаконцентратора можно выделить - «Offshore exploration technologies». Содержательная модель данного кластера представлена на рисунке 4.

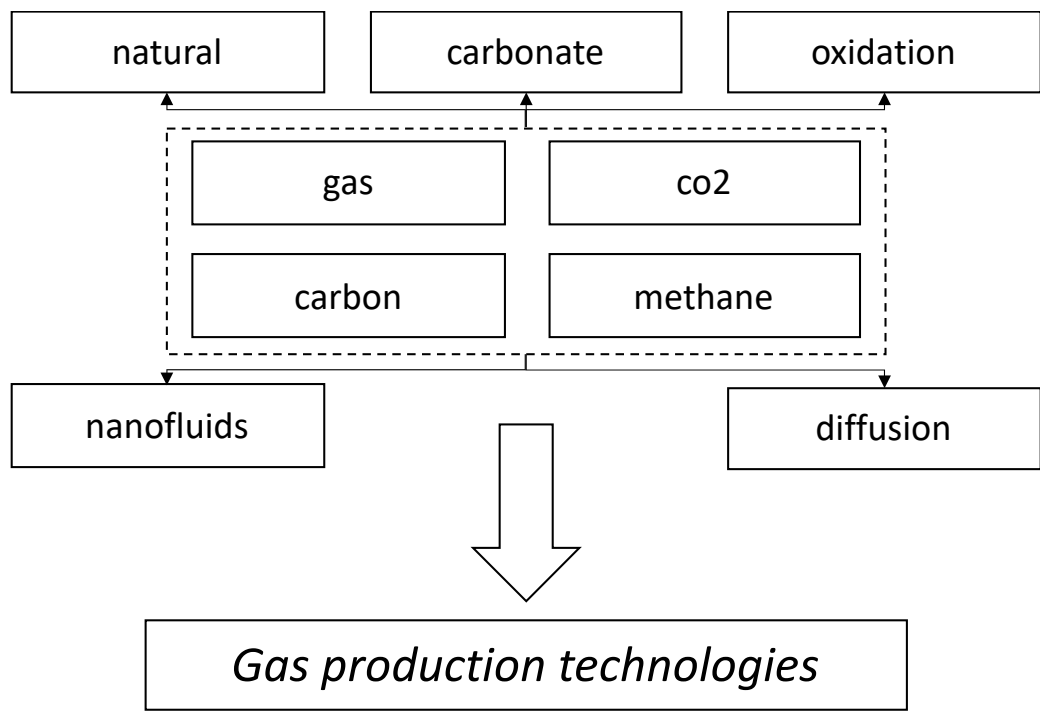

Рисунок 3. Содержательное модель кластера 3.

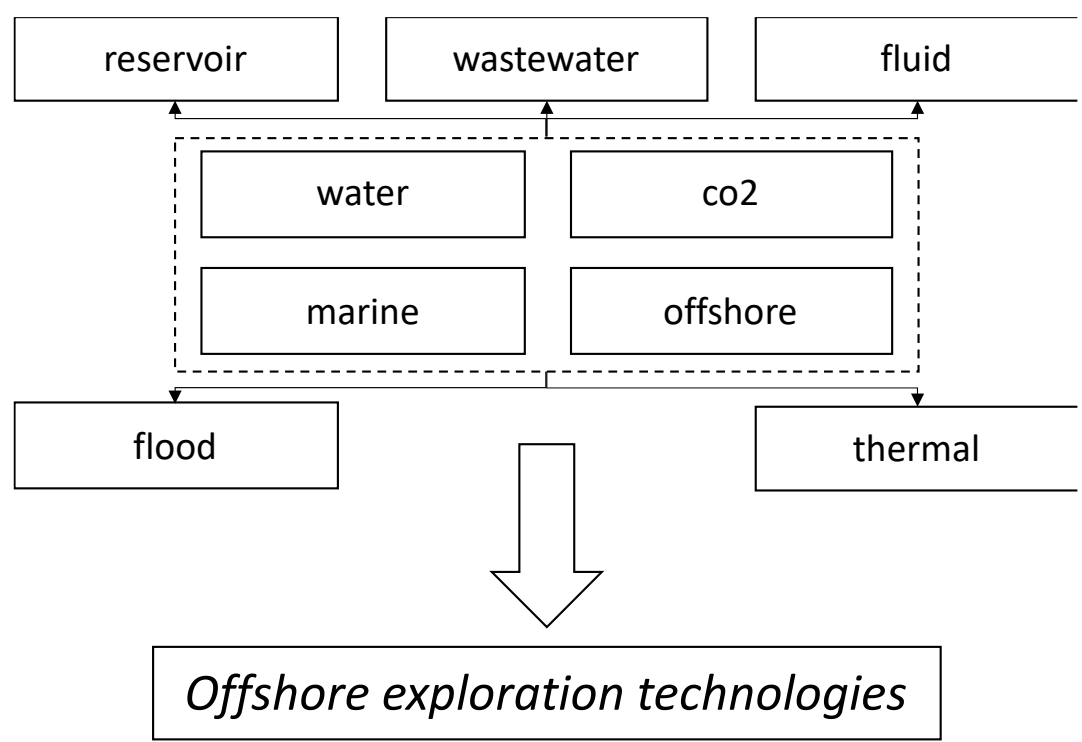

Рисунок 4. Содержательное модель кластера 4. 
Полученные кластеры описывают крайне объемный комплекс технологических решений, что в свою очередь определяет необходимость расчета показателей маркетинговой надежности в отношении содержательной и тональной компоненты. По каждому из выделенных токеновконцентраторов извлечены массивы новостной информации с 2010 по 2019 год включительно, в разрезе месяцев. Кластеризация извлеченных новостных массивов позволила идентифицировать кластеры, описывающие исключительно эффективную содержательную компоненту, а именно

- Кластер 1 - «future», «efficient», «advance», «sustainable», «innovative», «perfect» и многие другие токены.

- Кластер 2 - «solution», «future», «investment», «safety», «advanced», «development» и многие другие токены.

- Кластер 3 - «high», «change», «fund», «leader», «progress», «clean» и многие другие то- кены.

- Кластер 4 - «progress», «scientific», «investment», «future», «efficiency», «giant» и многие другие токены.

В таблице 1 представлены результаты оценки маркетинговой надежности в разрезе содержательной и тональной компонент.

Как можно видеть и с содержательной, и с тональной точки зрения явно выделяется наиболее и неимение маркетингово-надежные кластеры. На рисунке 5 представлена карта маркетинговой надежности.

В соответствии с анализом данной карты можно сделать следующие системные выводы относительно направлений развития лизинговой деятельности в сфере нефтепромыслового оборудования:

1. Наиболее перспективным направлением развития нефтепромыслового оборудования являются технологические решения в области добычи газа. С учетом того, также явно пер-

Таблица 1. Совокупность показателей маркетинговой надежности

\begin{tabular}{|c|c|c|c|c|}
\hline & \multicolumn{2}{|c|}{ M.R.C.content } & \multicolumn{2}{c|}{ M.R.C.tonality } \\
\cline { 2 - 5 } & $\begin{array}{c}\text { Фактическое } \\
\text { значение }\end{array}$ & $\begin{array}{c}\text { Нормированное } \\
\text { значение }\end{array}$ & $\begin{array}{c}\text { Фактическое } \\
\text { значение }\end{array}$ & $\begin{array}{c}\text { Нормированное } \\
\text { значение }\end{array}$ \\
\hline Кластер 1 & $-1,24 \mathrm{E}-07$ & 0 & 0,424 & 0 \\
\hline Кластер 2 & $1,59 \mathrm{E}-10$ & 0,332 & 0,573 & 0,281 \\
\hline Кластер 3 & $2,50 \mathrm{E}-07$ & 1 & 0,955 & 1 \\
\hline Кластер 4 & $-2,76 \mathrm{E}-10$ & 0,331 & 0,713 & 0,544 \\
\hline
\end{tabular}

M.R.C.tonality

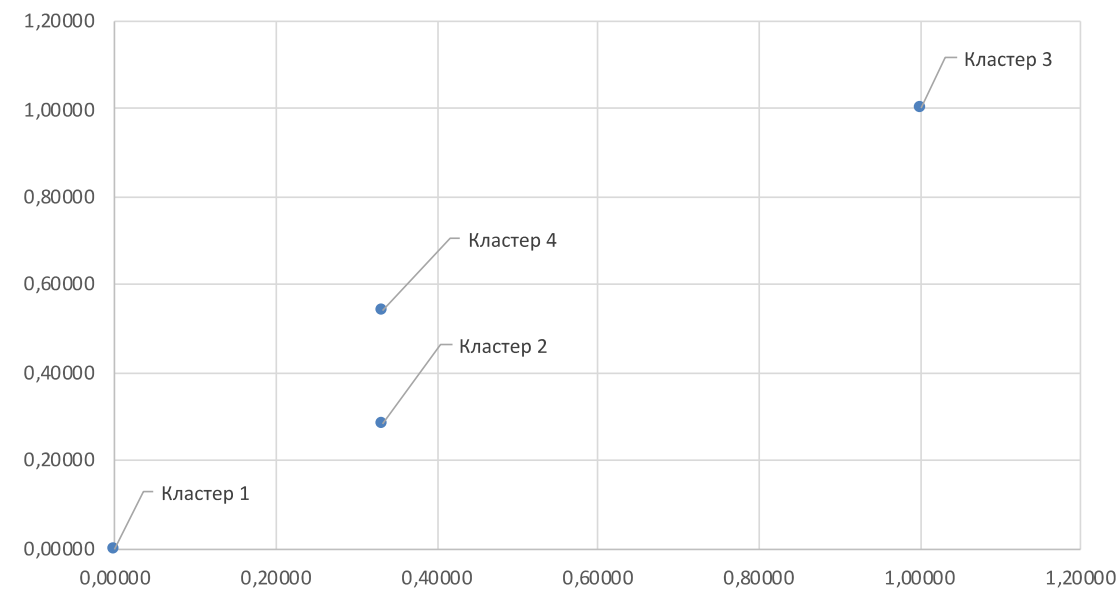

M.R.C.content

Рисунок 5. Карта маркетинговой надежности для 4 инновационных направлений развития нефтепромыслового оборудования. 
спективным направлением является морская добыча, можно сделать вывод, что в ближайшем будущем наиболее востребованы будут технологические решения в сфере добычи морского газа (вероятнее всего на арктическом шельфе).

2. Наименее перспективным технологическим направлением (из выделенных) являются противокоррозионные решения, основанные на нанотехнологиях. Данная специфика во многом обусловлена относительной универсальностью данного направления исследований, что не позволяет его специфицировать для целей лизинга нефтепромыслового оборудования.

Таким образом, можно заключить, что системное развитие предприятия, существующего в сфере лизинга нефтепромыслового оборудования может быть сформирована в рамках направления инвестиционного и исследовательского потока в область оборудования, предназначенного для морской добычи газа.

\section{Библиографический список}

1. Родионов Д.Г., Конников Е.А., Куракин В.И. Оценка маркетинговой надежности инновационных решений (на примере нефтепромыслового оборудования) // Экономические науки. 2020. № 193. С. 388-393.

2. Родионов Д.Г., Конников Е.А., Конникова О.А. Методология системного анализа информационной среды // Экономические науки. 2021. № 196. С. 160-174.

3. Родионов Д.Г., Конников Е. А., Мугутдинов Р. М. Системный анализ конкурентоспособности цифрового предприятия в рамках информационной среды // Экономические науки. 2020. № 193. С. 394-401.

4. Родионов Д.Г., Ялымов С. В., Конников Е. А. Влияние информационной среды на субъекты малого и среднего предпринимательства // Экономические науки. 2020. № 189. С. 86-91.

5. Родионов Д.Г., Конников Е.А., Алферьев Д.А. Информационный капитал предприятия как целевой показатель развития в рамках цифровых экономических систем // Экономические науки. 2020. № 190. С. 131 -137. 